\title{
Diesel combustion in high load situations: a visual analysis of mixture formation and air utilization
}

As fuel injection pressures keep rising, questions focus on additional benefits to be gained from the considerable efforts to achieve and handle the fuel pressure increments. The aim of fuel injection processes is to support the mixing of fuel molecules with oxygen. The steps towards this goal include fuel atomization, evaporation, heat transfer from air into the liquid or vaporized fuel together with transport of fuel for best air utilization. Engineering degrees of freedom include the parameters of the fuel injection system and handling of in-cylinder gas conditions. The paper describes basic high pressure flow processes, spray propagation, evaporation and combustion and the mixing of flame clouds with in-cylinder air for oxidation of high temperature soot particles. Experimental evidence of such processes is derived from laboratory flow tests as well as from optically accessed engines operated under conditions relevant for today's passenger car and heavy duty engines.

Key words: diesel engine, combustion, visual analysis

\section{Introduction}

Fuel injection pressures have been rising to well above 2000 bar as such high pressure injection still provides benefits for both fuel efficiency and emissions which outperform the efforts related to provide and control such high pressure systems. What is the reason that combustion benefits from the degrees of freedom provided by such high pressure injection systems? Which mechanisms relate the pressure drop along the nozzle hole with improvements then seen in the entire combustion chamber?

This paper gives a summary of effects studied in various experimental configurations, see Fig. 1, which are related to high pressure flow through the nozzle holes, the propagation and atomization of sprays as they enter the combustion chamber, heat and momentum transfer between in-cylinder gas and spray as well as ignition and combustion in normal Diesel engine combustion chambers.

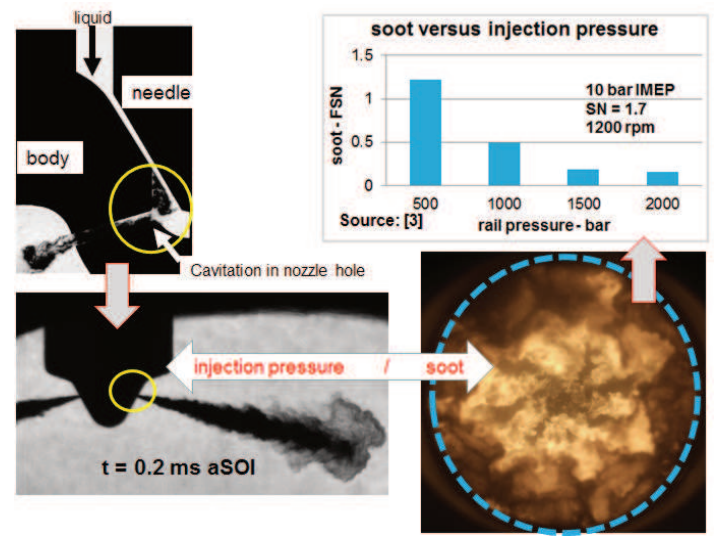

Fig. 1. The Diesel engine injection and combustion sequence. Example snapshots of cavitation in nozzle hole, spray injection, flame at end of injection and soot emissions trends related to injection pressure.

\section{Diesel flames}

The high luminosity of Diesel flames provides best conditions for flame observation by means of endoscopes together with high speed cameras. Endoscope access needs design adaptations and machining of the cylinder head, the technique is well established and suitable also for multicylinder engines. A comparison of diesel flames in a passenger car engine is given in Fig. 2. The examples for 4 and 8 bar IMEP give a view into the piston bowl and show the flame clouds rotating in the main, outer part of the bowl. In the 8 bar IMEP example with longer injection duration, there is a backflow of flame clouds into the center of the bowl.

The Diesel flame clouds as we see them in such movies or photographs comprise of soot particles being heated by the combustion process at a temperature of typically 2000 $\mathrm{K}$. Soot particles are formed in the fuel rich areas of the spray, their luminosity and spectral content reflect the temperature of their reactive environment. Soot clouds, consequently, form a 3D structure surrounding the initial spray and being propelled by the turbulent motion of the spray and gas phase. Soot oxidation takes place in oxygen rich high temperature areas of the combustion chamber. For effective soot oxidation, this implies the necessity to bring soot particles in contact with oxygen at a time well before combustion chamber temperature starts to decrease.

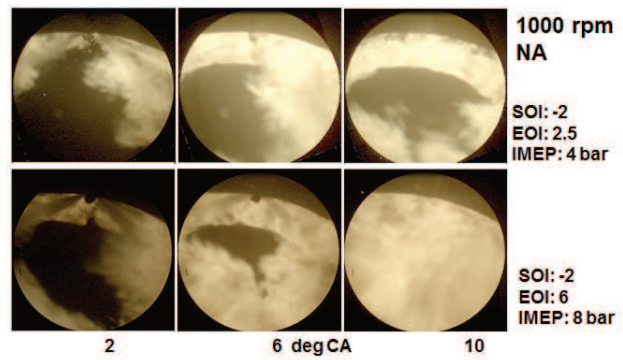

Fig. 2. Diesel flame motion in NA engine at $1000 \mathrm{rpm}$, view into piston bowl with endoscope and high speed camera

\section{Premixed flame in diesel combustion}

Ignition of Diesel flames occurs prior to the formation of soot clouds in a "premixed flame" giving rise to the typical premixed pressure peak followed by the main part of heat release. Such ignition is a gas phase event following the evaporation of fuel droplets and the further heating of fuel vapor in the hot surrounding air. Upon ignition, a typi- 
cal blue premixed flame is established. As is seen in Fig. 3, such premixed flames appear per each spray with some minor timing fluctuation due to the individual sprays' propagation and mixing fluctuations. In the Fig. 3 example, premixed flames are seen for about $100 \mu$ s before very luminous diffusion flame radiation starts to dominate.

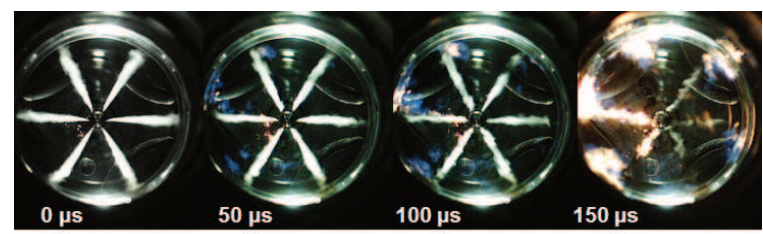

Fig. 3. Spray and flame sequence from a high speed movie with $50 \mu \mathrm{s}$ frame intervals taken at start of combustion. The premixed Diesel flame shows self ignition locations. Luminosity of these blue flames is very low. See also ref. [1]

\section{Spray evaporation}

Heat transfer from in-cylinder gas into the spray first off all yields fuel vapor before vapor then undergoes self ignition or is consumed by ongoing combustion. The evaporation process as shown in Fig. 4 (A) is accessible in optical research engines with Schlieren imaging techniques showing the boundaries between in -cylinder gas, fuel vapor and the optically dense spray core area. The time sequence in Fig. 4 shows stages of initial spray formation, fuel evaporation especially at the spray front and along the spray boundaries and finally the appearance of soot clouds at the spray tip. In this Schlieren imaging configuration soot is seen by its absorption of the background illumination.

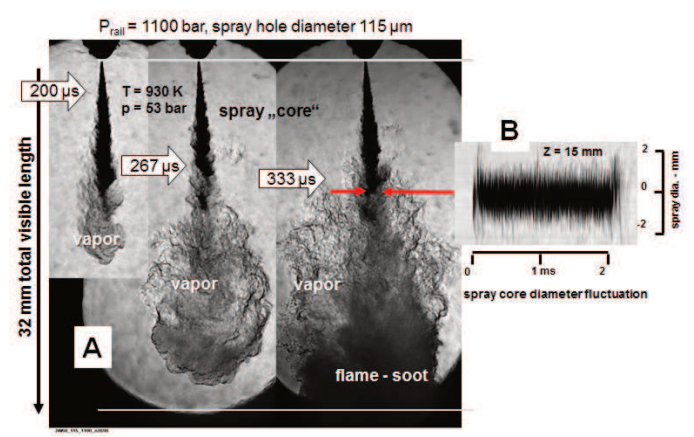

Fig. 4. (A) Diesel spray in an optical research engine with spray ,core“ comprising fuel droplets, fuel vapor seen with Schlieren illumination and shadow of soot clouds. (B) spray core diameter fluctuations show spray turbulence effects introduced at the injection process. Via heat and momentum transfer, compressed hot in-cylinder air controls spray core length, vapor formation and ignition

\section{Spray atomization}

Spray atomization is initiated as liquid fuel passes through the nozzle hole. The high pressure flow events introduce turbulence which results in the macroscopic spray cone angle downstream of the orifice and in the turbulent flow of spray ligaments and droplets forming the "spray core". Spray core diameter fluctuations are then a consequence of turbulence, an example is shown in Fig. 4 (B).

The source of spray turbulence is related to the high pressure fuel flow into and through the nozzle hole. At injection pressures above a few 100 bar and with usual nozzle hole geometry configurations, the local pressure gradients inside the nozzle hole give rise to cavitation [2 ilass]. The gas bubbles created at this cavitation process, their collapse inside the nozzle hole or otherwise their transport into the combustion chamber contribute to turbulent spray motion introducing spray breakup and atomization. Spray core diameter fluctuations as shown in Fig. 4 (B) are a consequence of such turbulent spray motion.

\section{Spray core}

With above described spray features, the definition of "spray core" is essentially related to observations in optical research engines. Spray core length as seen in the photographs of Fig. 4 or in the time resolved shadow traces of Fig. 5 are related to the attenuation of light used for back illumination of the spray. With this pragmatic definition of a spray core, its length is under the influence of spray evaporation and thus heat transfer from the compressed gas into the spray.

A practical consequence of such gas temperature and heat transfer effects is the absence or presence of liquid fuel film deposition on a piston bowl wall, see Fig. $5(\mathrm{C})$. At low engine temperature with slow fuel evaporation, the spray core over many injection and combustion cycles can establish a wetted piston surface. The same engine at normal temperature shows only marginal impingement of liquid fuel.

The influence of injection pressure on spray core length is shown in Fig. 6 with examples collected in a research engine. At constant, compressed, hot gas conditions, injection pressure has very low influence on spray core length. However, injection pressure transfers to spray momentum. This momentum is preserved with the spray vapor and finally the soot cloud penetrating deeper into the combustion chamber.

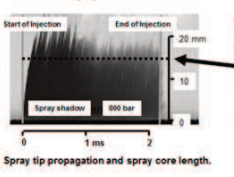

B

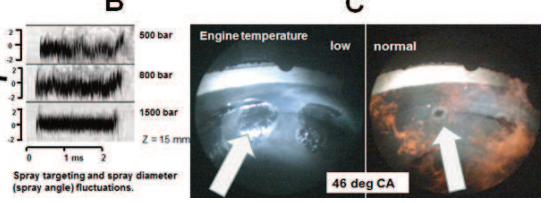

Fig. 5. spray core dynamics recorded (A) along and (B) across the spray axis from start to end of injection. Injection pressure has influence on fluctuation frequency of spray core diameter. In normal engine (C) temperature influence on spray core length is responsible for piston surface wetting in cold engine

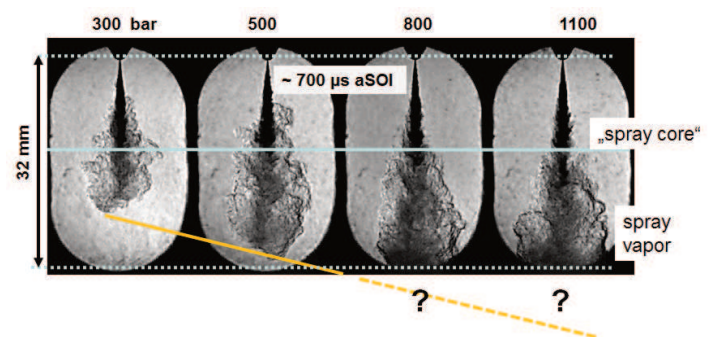

Fig. 6. spray core and spray vapor plumes under influence of injection pressure. Snapshots at about $700 \mu \mathrm{s}$ aSOI

\section{Injection pressure - air utilization - soot emissions}

Flame motion in the entire piston bowl area can be observed in optical Diesel engines with elongated piston configurations and optical windows forming the bottom part of the piston bowl. Such engine designs can provide original 
combustion chamber geometry conditions as well as highly realistic combustion cycles as is described in ref. [1].

Recording the diffusion flame patterns with a high speed camera shows formation and growth of the soot clouds related to each spray and the transport of these soot clouds under the influence of injection and in-cylinder gas motion. Finally, the visible soot clouds disappear as a combined result of soot oxidation and cooling of surviving soot particles.

Engine out soot, thus is the result of soot format and oxidation. With ignition delay in normal Diesel combustion systems much shorter than injection duration, there is massive formation of soot particles as mixing prior to combustion is ineffective. Consequently, the focus on achieving low engine out soot levels is on enabling maximum soot oxidation.

This oxidation needs the soot particles which are formed in the fuel rich flame areas to meet with oxygen or with oxidizer molecules such as $\mathrm{OH}$. The soot - oxygen mixing furthermore must be supported by sufficiently high temperatures to initiate the oxidation process.

When following the flame formation and flame propagation events as are easily seen in high speed movies, it is evident that diffusion flame clouds formed along the spray plumes need to mix with the air present between the individual flame clouds and between flame clouds and combustion chamber surfaces.

A simple way to visualize the flow field related to the growth, transport and mixing of the complex 3D flame "surface" structure is to apply PIV evaluation software to subsequent frames of flame movies. This method has been introduced by Dembinski [3]. Application of such method to combustion cycles with short and long duration of injection is shown in the examples of Fig. 7.

The flame flow fields during injection in Fig. 7 (A) show the growth of the flame clouds and their radial motion towards the piston bowl wall. Near the wall the flame clouds respond to the swirl rotation of the in-cylinder air and bend into a rotational motion along the piston bowl wall.

In the high load examples of Fig. 7 (C), with more than twice as long injection duration, the flame clouds are reflected off the piston bowl wall and move back into the center of the combustion chamber. The flow field taken just after the end of injection now shows the backflow motion and a speedup of flame rotation in the combustion chamber center. This speedup of the central swirl motion has been explained by Dembinski to be caused by conservation of angular momentum as rotating gas is moving into the swirl center [3].

The effect of injection pressure on these flame transport and mixing events arises from the sprays' momentum. As this momentum is transferred into the vapor and flame clouds, reflection of a high velocity flame cloud back off the piston bowl wall yields faster mixing of the flame cloud with air in the bowl center.

Together with this large scale flame transport mechanism, turbulent flame and gas motion adds to the small scale mixing of soot particles and reactive gas.

Evaluation of the flame flow field data for turbulence effects has been done by Dembinski [1, 3]. His examples are reproduced in Fig. 8. They compare local turbulence distribution for combustion cycles with 500 and 1000 bar injection pressure, respectively. Clearly, higher injection pressure yields higher turbulence activity. The benefit of high turbulence, however is just present during injection and for a very short period after the end of injection. The mean kinetic energy plot over crank angle degrees shows kinetic energy to dissipate within about 5 deg CA following the end of injection.

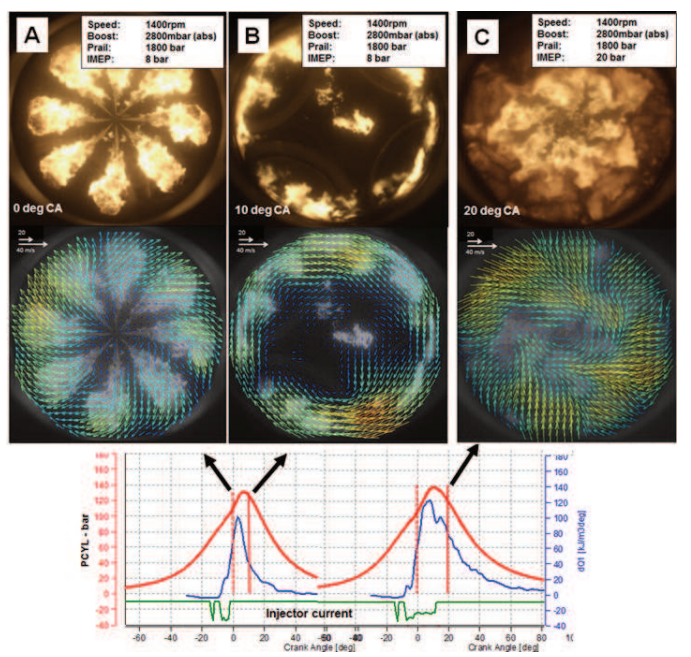

Fig. 7. Diesel flames and flame velocity fields in the piston bowl of an optically accessed heavy duty Diesel engine. Same injection pressure at 10 and 20 bar IMEP. Long DOI at 20 bar IMEP result in backflow of flames into the bowl center and speedup of center swirl motion

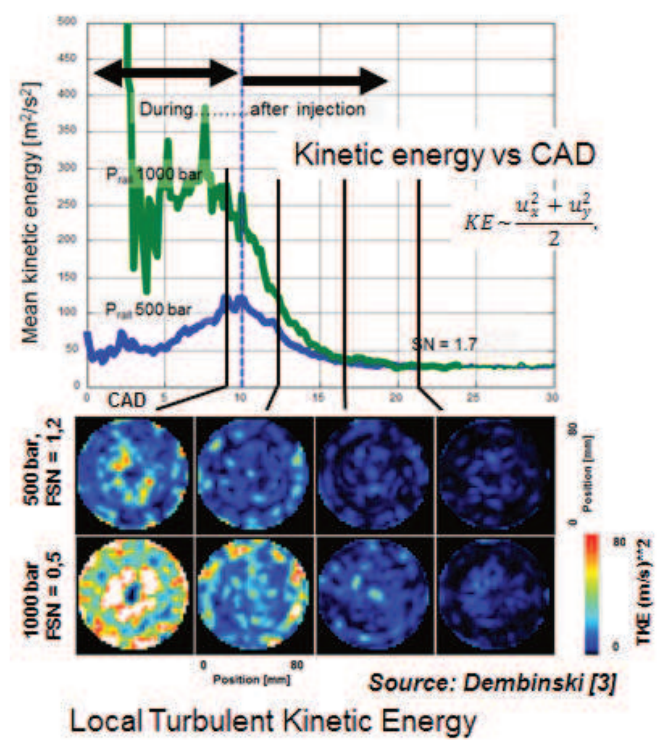

Fig. 8. Turbulent kinetic energy evaluation on basis of flame flow field data for 500 and 1000 bar injection pressure $[1,3]$. Notice the fast decay of turbulence after end of injection

\section{Injection for fast soot oxidation - summary}

Above examples summarize experimental evidence on Diesel fuel injection and combustion with focus given to the clarification of mechanisms starting with the injection process and leading up to soot oxidation and emission of soot particles.

Fuel injection pressure has been shown to be one of the means available to engine development in controlling the 
mixing of the reactants during and after injection. Following points have been emphasized:

- The formation of a highly turbulent spray supported by flow cavitation as fuel is injected at pressures exceeding a few hundred bar.

- Formation of the spray core mainly comprising fuel droplets.

- Formation of a fuel vapor plume as the spray core evaporates.

- Ignition of fuel vapor in a premixed flame being followed by combustion in the fuel rich part of the spray.

- Formation of the luminous Diesel flame with soot particles acting as very bright tracers of high temperature activity.

- Transport of the diffusion flames as given by the combined influence of spray momentum, in-cylinder air motion and combustion chamber surfaces.

The role of spray momentum and thus of fuel injection pressure for transport and mixing processes and especially the importance of fast mixing of reactants for effective soot oxidation was explained with experimental material collected in realistic Diesel engine combustion situations.

\section{Experimental facilities - summary}

Diesel combustion situations have been studied in optically access engines as shown in Fig. 9. Engine concepts and design details allow for maximum optical access with a glass liner ring and a full optical piston, or access to the piston bowl with a metal piston and a bottom glass window. Such engines have been used at cylinder pressures up to 160 bar.

In normal engines, optical access is achieved with endoscope inserts into the cylinder head. Endoscope windows are designed to allow cylinder pressures above 200 bar.

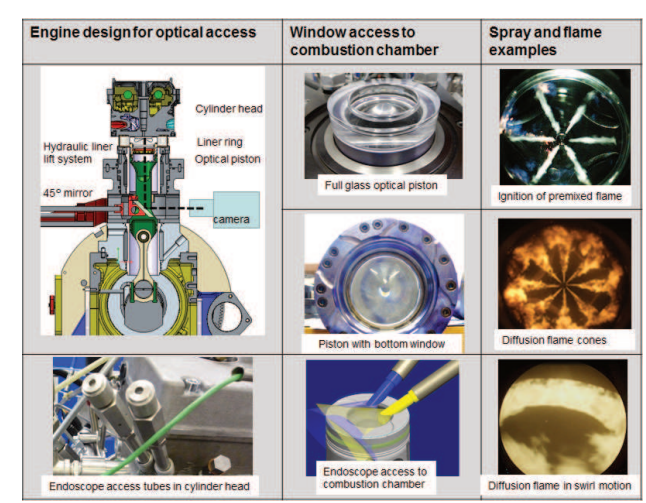

Fig. 9. Optical access in research Diesel engines with elongated piston and piston bowl windows. Endoscope access in cylinder head of normal engines. Visualization examples for each of these engines

Operation of such engines, especially in high load conditions requires frequent cleaning of window surfaces. In order to minimize the need for cleaning, such engines are preconditioned for target temperatures. They are furthermore operated in motored mode until engine speed and intake manifold pressure have stabilized. Then, for a few cycles, injection is activated with simultaneous recording of all data and camera records of interest.

In high load tests after start of fired operation, only the first few cycles are used for data evaluation Progressive blackening of window surfaces prohibits useful operation for more than about 10 fired cycles.

Access to the combustion chamber for removing the soot layers and cleaning window surfaces is achieved with hydraulic cylinder liner lift devices. The total time from stopping such optical engine, cleaning the combustion chamber and preparing the engine for re-start can be as short as 6 minutes.

\section{Nomenclature}

$\begin{array}{ll}\text { aSOI, SOI } & \text { (after) start of injection } \\ \text { EOI } & \text { end of injection } \\ \text { DOI } & \text { duration of injection } \\ \text { IMEP } & \begin{array}{l}\text { indicated mean effective pressure } \\ \text { SN }\end{array} \\ \text { swirl number }\end{array}$

\section{Bibliography}

[1] DEMBINSKI, H., ANGSTROM, H.-E., WINKLHOFER, E. Injection pressure as a means to guide air utilization in Diesel engine combustion. Fuel systems for IC engines. Institution of Mechanical Engineers. 2014.
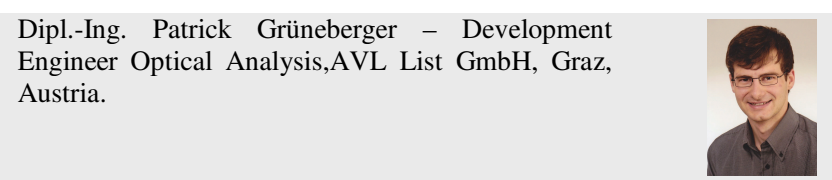

Dipl.-Ing. Bernhard Jocham - Development Engineer Optical Analysis, AVL List GmbH, Graz, Austria.
FSN

NA

CA, CAD

TKE, KE

Prail filter smoke number

naturally aspirated

crank angle (degree)

(turbulent) kinetic energy

fuel rail pressure

[2] WINKLHOFER, E., KELZ, E., MOROZOV, A. Basic flow processes in high pressure fuel injection equipment. ICLASS. 2003, Italy.

[3] DEMBINSKI, H. In-cylinder flow characterization of heavy duty diesel engines using combustion image velocimetry. Doctoral thesis, Royal Institute of Technology. Stockholm, 2013.

\footnotetext{
Ernst Winklhofer, DEng. - Manager Combustion Measurement and Optical Technologies, AVL List $\mathrm{GmbH}$, Graz, Austria.

e-mail: Ernst.Winklhofer@avl.com
}

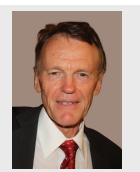

